\title{
Submission and Peer Review of Learning Objects Using a Community-Based Repository
}

\author{
Ilona Box \\ University of Western Sydney, Penrith, NSW
}

\section{i.box@uws.edu.au}

\begin{abstract}
A community-based learning object repository supports the sharing and collaboration of learning object development within discipline or topic area communities. The repository is built using an object-oriented method and implemented using JADE, an object-oriented technology platform. The repository is a software system aimed at improving the creation, collection, quality assurance, and ultimately the accessibility of learning objects.

The initiatives regarding learning objects and the double blind review process for research publications are the two key influences on the learning object repository design. The repository is a significant advance on existing learning object technology as 1) it is built using an objectoriented method and platform including the database; typically learning object collections are stored in relational databases, and 2) it incorporates an automated submission and double blind peer review process before learning objects are made public.
\end{abstract}

The use of the repository by the learning object creators, reviewers, moderators, administrators and educators will determine the success of the product.

Keywords: Object-orientation, learning object repository, learning objects, double blind review, peer review, JADE, IEEE LOM

\section{Introduction}

Listening to John Bell present his paper (Bell, 2003) at the Australasian Computing Education conference left me wondering about yet another word in the IT lexicon that had taken on a different and yet overlapping meaning. The word was "object". Bell and many others, in the context of computer systems built to support the use of learning objects (LOs), do not mention objectorientation. Yet, the overlapping concepts behind learning objects and object orientation do suggest that object-orientation would be an appropriate approach to use.

From the perspective of a learning object repository, a learning object (LO) is any material digital or non-digital that is designed and supplied to aid teaching and learning. Some people limit the definition to only digital media as LOs are typically delivered electronically. From the point

Material published as part of these proceedings, either on-line or in print, is copyrighted by Informing Science. Permission to make digital or paper copy of part or all of these works for personal or classroom use is granted without fee provided that the copies are not made or distributed for profit or commercial advantage AND that copies 1) bear this notice in full and 2) give the full citation on the first page. It is permissible to abstract these works so long as credit is given. To copy in all other cases or to republish or to post on a server or to redistribute to lists requires specific permission from the publisher at Publisher@InformingScience.org of view of the community based learning object repository a LO can be of any size, of any type, in digital or nondigital form for use, and digitally stored, such as, a five-minute in-class exercise, the lesson plan for a twohour class, a set of lecture notes on a topic, or a complete multimedia interactive course. In this early stage of 
development we worked with the term "courseware" rather than "learning object" to differentiate it from "software object". From the perspective of the object-oriented paradigm, a LO is an encapsulated, polymorphic, reusable thing; characteristics or concepts that are typical of a software object. This commonality is one reason for pursuing an object-oriented community-based learning object repository.

There is recognition that scholarship in university teaching requires better and more formal recognition than it currently receives (Taylor \& Richardson, 2001). The use of double blind peer review for the LO repository was chosen as it emulates the review process of respected research publications. A double blind peer review process is when the author, or creator, and reviewer remain anonymous. The $\mathrm{LO}$ creator becomes known when the $\mathrm{LO}$ is released to the public, i.e. the community of educators.

The community-based aspect of the LO repository is an attempt at addressing a major problem facing the use of learning objects. The Taylor project (Taylor \& Richardson, 2001) has stalled at the second stage because it is not being used. It also contains bottlenecks in the review process, relying on journal editors to mediate the open, not blind, review process. The reliance on a community to make the LO repository work is an idea worth pursuing.

The ideas of object orientation, double blind peer review, and community-based management are combined to develop a LO repository software product. This paper describes this product and so contributes to the ongoing development of workable learning object repositories.

\section{Overview of the Repository}

An overview of the repository is presented followed by the processes to submit and review LOs. The community based LO repository has two sides, a private side and a public side, shown in Figure 1. The private side is where submissions and reviews of LOs are supported. The public side is where learning objects are downloaded or connected for use by educators. The roles of editors, moderators, administrators, hosts, critics, and requestors are necessary, though at this stage not included in the product. The LO submission process has received the most attention. Other modules currently being

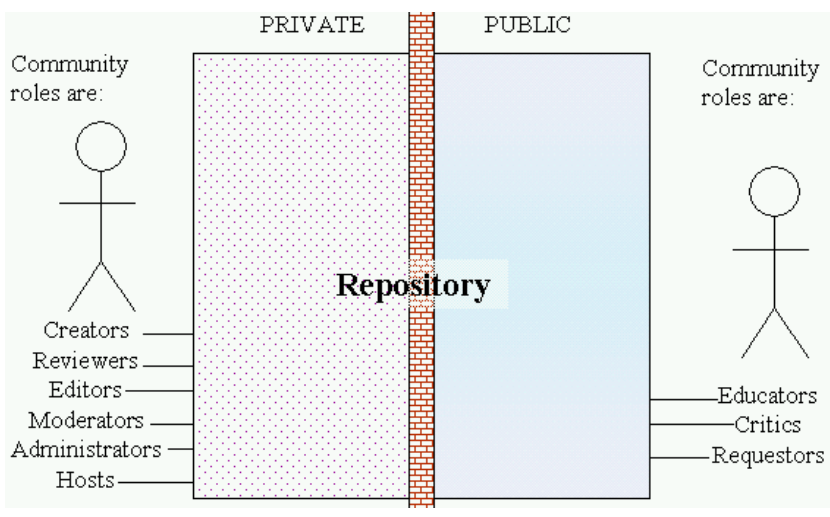

Figure 1: Overview of the community based LO repository developed are the review process and email messaging.

The automation of as many processes as possible, thus minimizing the human intervention required, such as messaging, is also a feature of this LO repository. The ability of the repository to respond to triggers other than human interaction is considered essential to its success.

\section{Learning Object Submission and Review Processes}

LO submission and review are the critical processes on the private side of the LO repository. These processes are shown in the use case diagram, Figure 2. The creators and reviewers need to first subscribe to the repository by completing a profile. The "Add subscription" use case is incomplete. This use case includes the profiling process that users need to complete so the system can support them in the best way possible. 


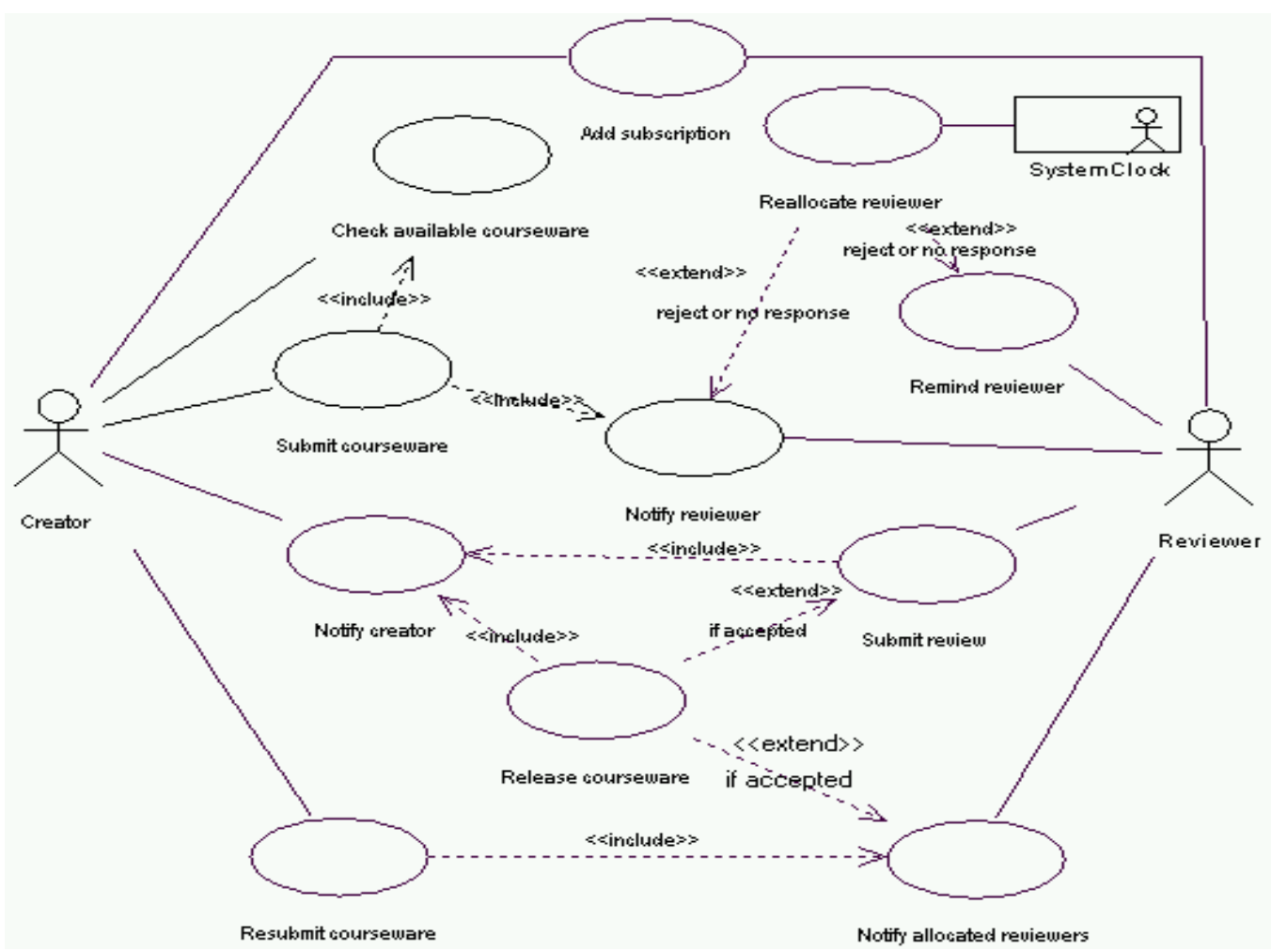

Figure 2: Community based LO repository partial use case diagram

\section{Learning Object Submission}

LO submission is the module that has been developed. The submission process requires creators to be subscribed to the system. The use cases that form the LO submission module are "Submit courseware", "Check available courseware", and "Resubmit courseware". The LO submission process requires a creator to complete a number of interfaces. Not only does a creator need to upload the LO, additional information to make it accessible is required, i.e. the LO metadata. The creator, via the interfaces, supplies the metadata.

There are a number of standards of metadata that should accompany a LO. At this stage no particular standard is used in the LO repository. Implementing, the IEEE International Metadata Standard for LOs, which is becoming the worldwide standard (McGreal, 2004), is a consideration for the future.

The interfaces a creator (also known as contributor and submitter) completes are shown in Figures $3 \mathrm{a}$ to $3 \mathrm{e}$. In Figures $3 \mathrm{a}$ to $3 \mathrm{e}$, the creator needs to consider each entry as a means for someone to locate the particular LO. Each entry may be used in a search on either the public or private sides of the repository. The following discussion is on the enhancements these panes require.

In Figure 3a, the additional information is more than what would be normally requested for an electronic research publication submission. This additional data entry has lead the development team to consider a standalone data entry module that allows the contributors to write their entries and then upload the file into the repository, for final viewing in these panes before submitting. The stand-alone module would be easier than requiring the creator to remain online and connected to the repository. 


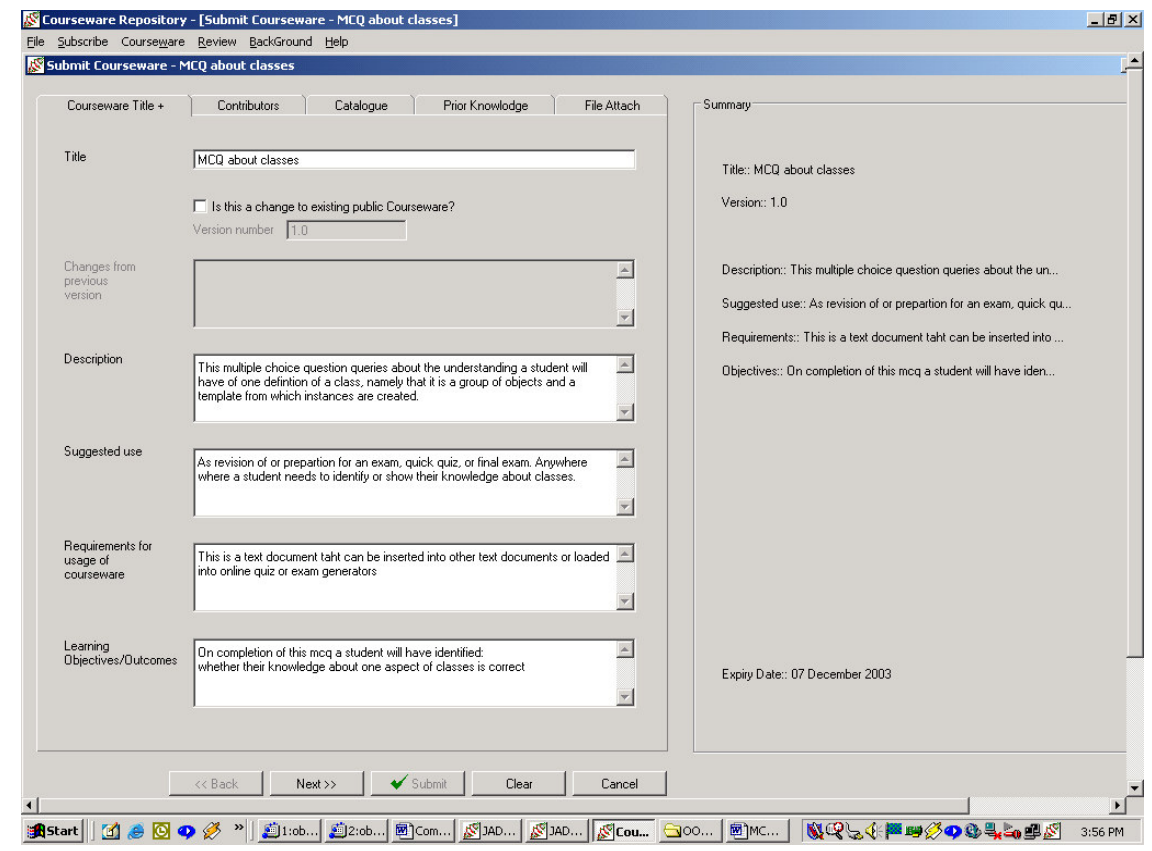

Figure 3a: Pane 1 of the LO submission process.

In Figure 3b, the contributors are identified. An extra requirement of this pane is to allow the entry of the percentage contribution of each contributor and to be able to select contributors wishing to receive email messages related to this particular LO submission.

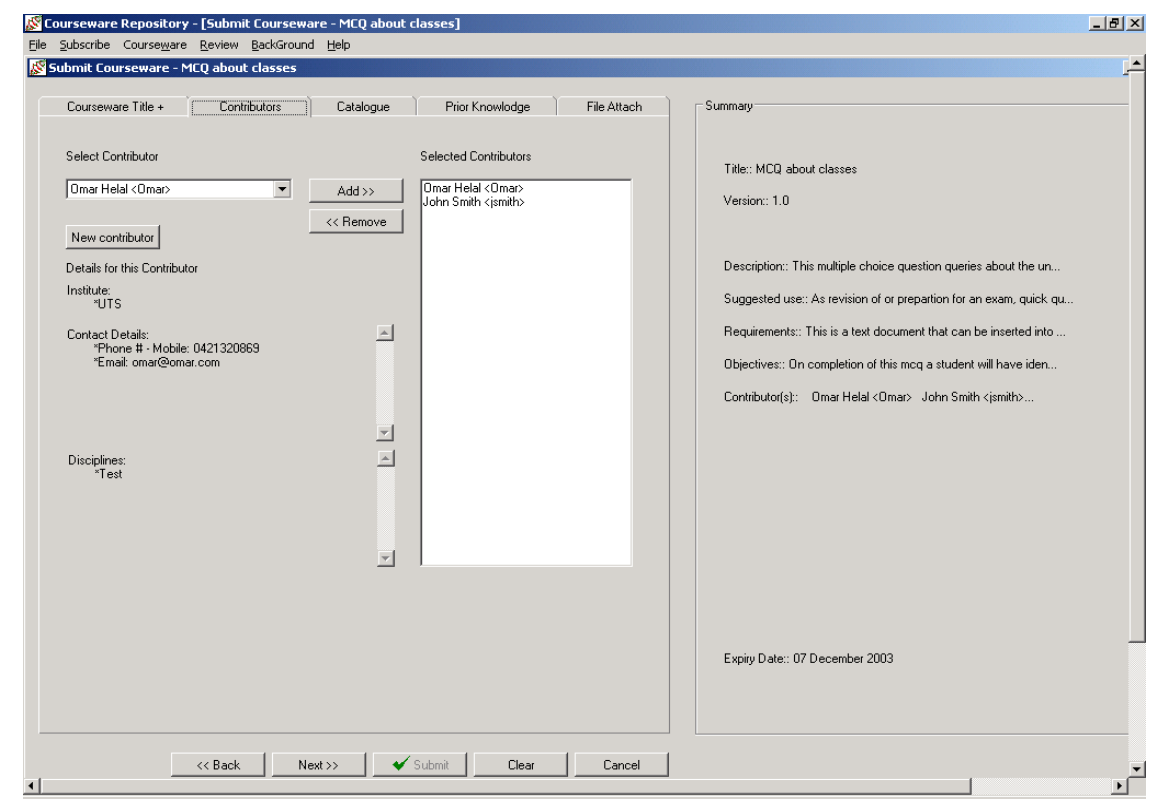

Figure 3b: Pane 2 of the LO submission process.

In Figure 3c, the creator suggests how the LO is to be catalogued. Catalogue choice is related to the community; they choose which catalogue to use. In another module of the LO repository, catalogues are mapped so that one catalogue entry search can be used to find material catalogued in other catalogues. 


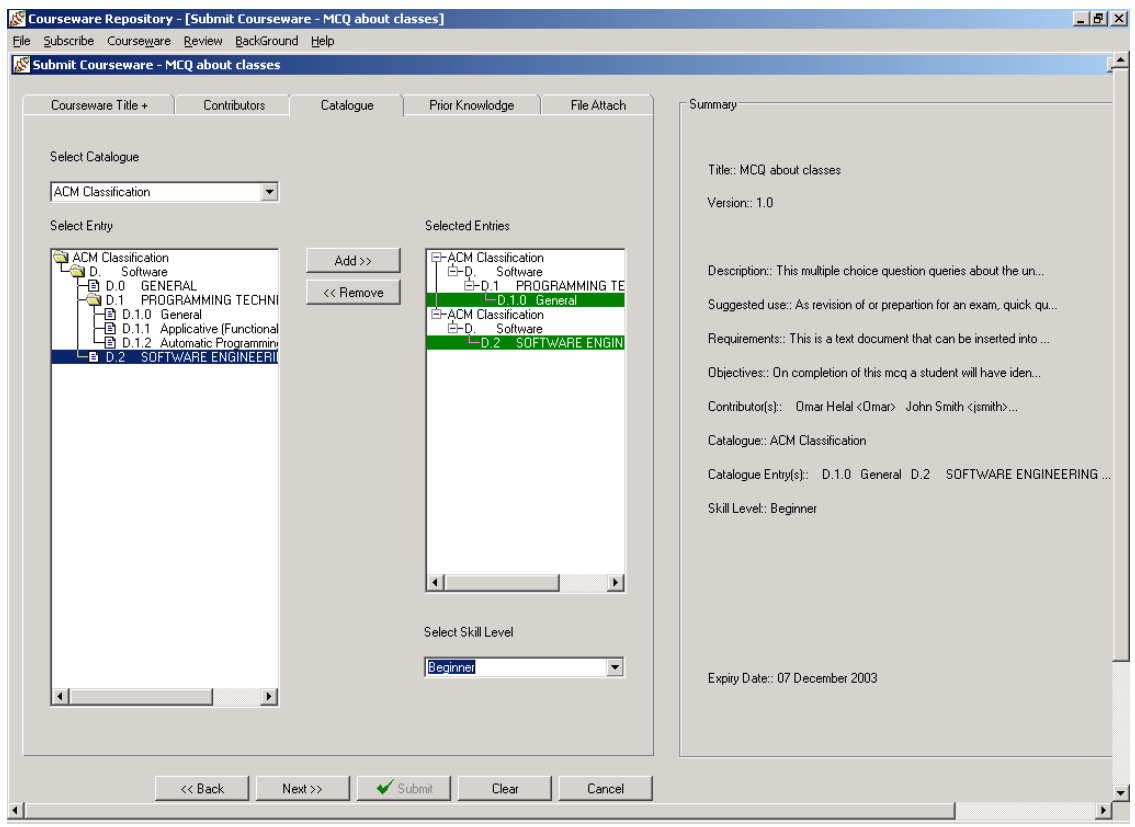

Figure 3c: Pane 3 of the LO submission process.

In Figure 3d, the prior knowledge required is shown by using catalogue entries. Additional description and an indication for "no prior knowledge needed" are outstanding requirements for this pane.

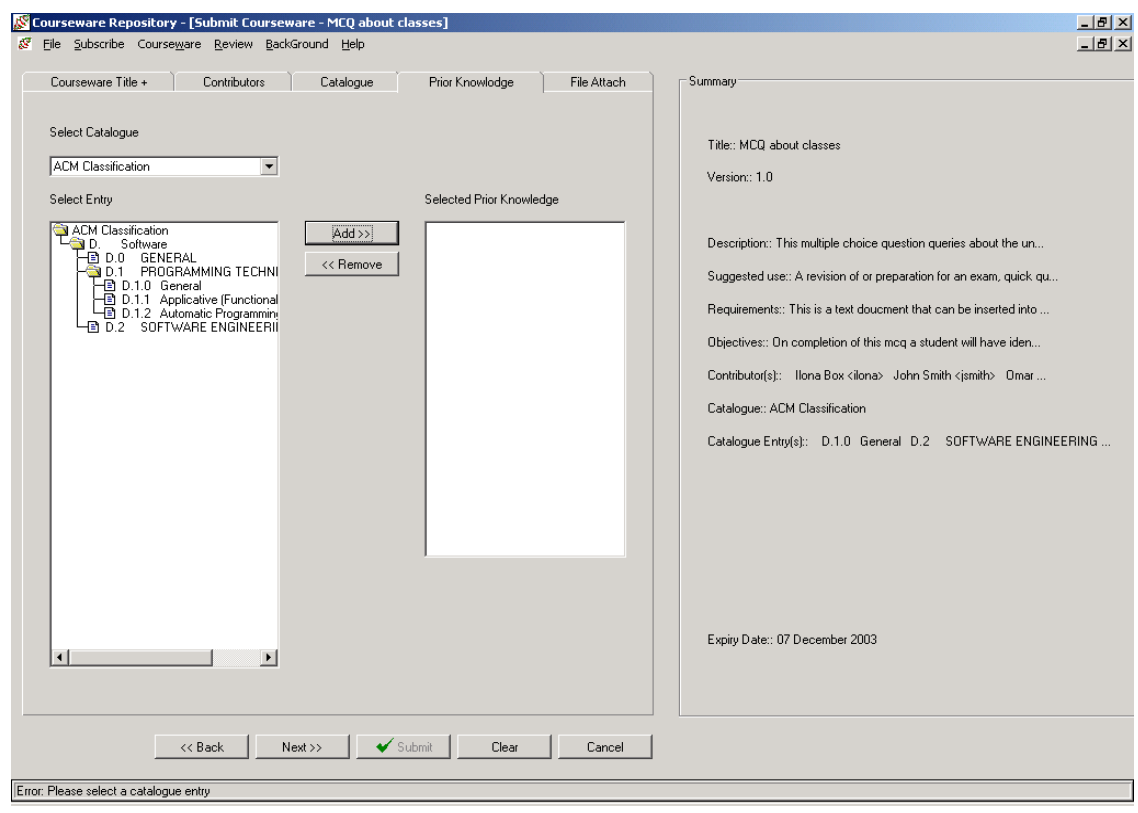

Figure 3d: Pane 4 of the LO submission process.

In Figure 3e, the submitter indicates the file or files that contain the actual LO. The pedagogical type, such as multiple choice questions, small group exercise, and lecture notes, the language in which the LO is written and the date by which the submitter would like the LO reviewed. 


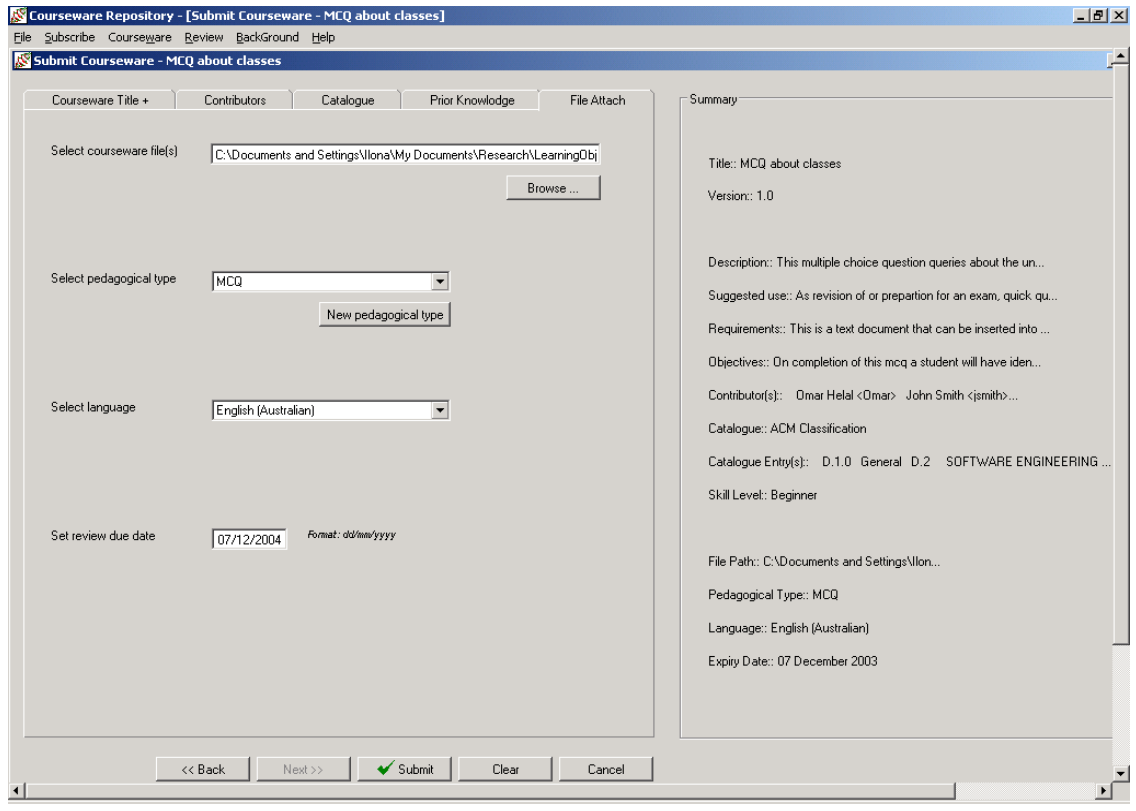

Figure 3e: Pane 5 of the LO submission process.

The summary on the right of each pane shown in Figures 3a to 3e is hyperlinked (Figure 4) to the data entry point on the appropriate pane. This lets the submitter navigate easily without having to remember what is on each pane.

The versioning of a $\mathrm{LO}$ is dealt with in the first pane, Figure 3a. It is the public LO that receives an increment of a whole number. Using the decimals for versioning within the private side of the repository is useful for identifying resubmitted and reviewer versions of a LO.

The LO submission process requires creators to contribute their work in such a way that others are likely to find and use the

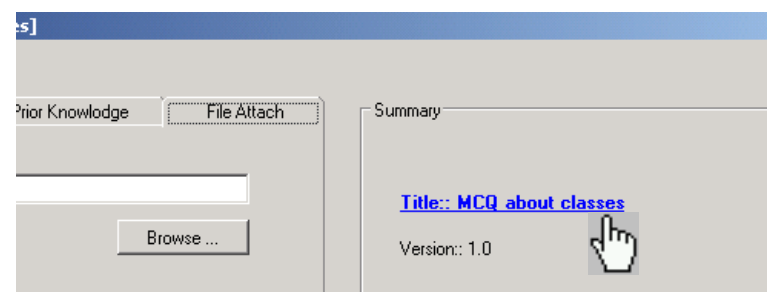

Figure 4: The summary is hyperlinked to the entry point on the appropriate pane. LO. Reviewers assess the quality of the LO before it is made public.

\section{Learning Object Peer Review}

The LO review module is incomplete. The pane in Figure 5 is an example of what we consider is appropriate. The reviewer can also make free text entries. A more complex process that allows the reviewer to edit the LO files and additional information is being designed and built.

The review process is automated as much as possible. The reviewers are selected based on their profile and current reviewing load. A reviewer is emailed the request to review the submitted LO as well as an option to immediately decline the request. The request to review allows the reviewer to go to the LO, the request functioning in a way similar to an active URL in an e-mail message. The immediate decline of the request to review would send a trigger to the repository to allocate another reviewer. For the same reason of being able to work offline that was stated for a stand-alone module for submission, we would like a stand-alone module for reviewing. Once a 


\begin{tabular}{|c|c|c|c|c|}
\hline Assessment & Comments & Quality St: & & Overall Recommendation \\
\hline Criterion & Poor & Fair & Good & Excellent \\
\hline \multicolumn{5}{|l|}{ Assessment } \\
\hline Clarity, coherence and organisation of writing & $\mathrm{C}$ & $\mathrm{C}$ & $\mathrm{C}$ & 6 \\
\hline Relevance to catalogue & $\mathrm{c}$ & $c$ & $c$ & $c$ \\
\hline $\begin{array}{l}\text { Potential to stimulate usage among } \\
\text { catalogue participants }\end{array}$ & $c$ & $\mathrm{c}$ & $c$ & c \\
\hline Relevance and utility to participants & c & $c$ & $\mathrm{C}$ & c \\
\hline $\begin{array}{l}\text { Contribution to scholarship and/or } \\
\text { innovative practice in higher education }\end{array}$ & $\mathrm{c}$ & $\mathrm{c}$ & c & c \\
\hline $\begin{array}{l}\text { Knowledge of current thinking, research, } \\
\text { policy and/or practice with an underpinning } \\
\text { theoretical framework }\end{array}$ & $c$ & $c$ & c & $c$ \\
\hline $\begin{array}{l}\text { Appropriate application of research } \\
\text { methodology and/or conceptual framework }\end{array}$ & c & c & $c$ & c \\
\hline
\end{tabular}

\section{Figure 5: Review criteria scored against a Likert scale.}

reviewer indicates their review is complete. Contributors are notified by email that the review is complete.

\section{Profiling}

When a user subscribes to the Lo repository, it is important that they complete a profile. The system will use the information to send messages at the right time. For instance, a reviewer, when subscribing nominates that they will reply to a review request within two days. The reviewer is sent a review request. The system does not receive an immediate decline trigger nor does the re-

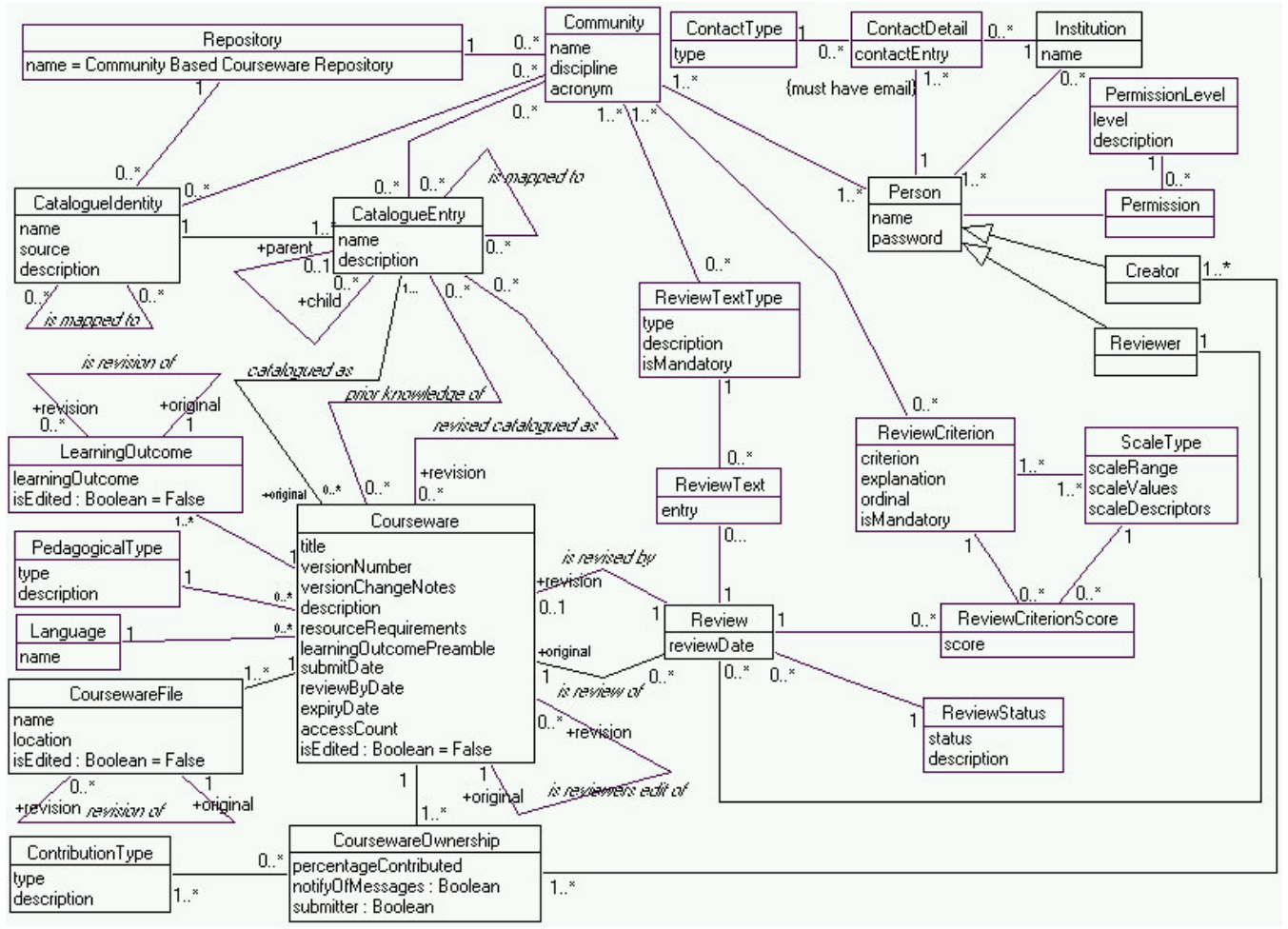

Figure 6: The class diagram for the community based courseware repository as at $30^{\text {th }}$ November 2003 
viewer request to start the review within the two days. Therefore, based on the reviewer's profile, the system reallocates the review to another reviewer.

\section{Future Development}

The LO submission process is at a stage where it can be presented to focus groups to consider its usability, functionality and aesthetics. The outcomes would provide further refinements and requirements, which we hope would improve the success of the application.

The current class diagram, Figure 6, shows that the structure of the system is complex, especially when understanding the unary associations. There is someway to go before it is complete. The implementation of profiling and community customization of the review process of the module is to be developed after the submission and review processes. The development team feels that the presentation of the product in its current form will inform us as to the value of continuing development.

\section{Conclusion}

The success of any learning object repository depends on the contribution of LOs. There are projects that have failed because LOs were not submitted. By making this LO repository community based it is hoped that the community will build and benefit from their own contributions.

We are automating processes as much as possible. The LO repository is designed to minimize the human intervention necessary to take-in, distribute, search, and access LOs.

The system is built so that it can be easily incorporated into the users' work. Many learning object and online course delivery systems are separate from and therefore extra work for the users current work practices. By using an existing communication method, i.e. email, and profiling, we have designed to integrate using the LO repository into existing work practices.

The incentives to contribute LOs are few, for now. With the establishment of national learning and teaching institutions, which can reward LO publication in the same way research publications are rewarded, the incentives will increase. Another incentive is the sale of LOs. The standardization of digital learning objects, and online learning systems that can use them, will make the sale of LOs possible.

\section{Acknowledgements}

I would like to acknowledge to contribution of the volunteer undergraduate students for their efforts, great and small: Omar Helal, Matthew Keyte, Jason Pereira, Daniel Chhuy, Ibal El-Miski, Mary Sassine, and Frank Camilleri.

\section{References}

Bell, J. (2003). The WEBWORKFORCE - A learning repository to support educators, trainers and Information Technology courses. The Fifth Australasian Computing Education Conference (ACE2003), Adelaide, South Australia.

McGreal, R. (2004). A primer on metadata standards. Seminar presentation with I. Box. Sydney.

Taylor, P. G., \& Richardson, A. S. (2001). Validating scholarship in university teaching: Constructing a national scheme for external peer review of ICT-based teaching and learning resources (No. 01/3, DETYA No. 6683.HERC01A). Australia: Department of Education, Training and Youth Affairs, Evaluations and Investigations Programme, Higher Education Division. 


\section{Biography}

Ilona Box is an author and academic. Object-Oriented Software Development: Step by Step was published in 2002 and has received many favorable comments from its readers. Working within the School of Computing and IT, University of Western Sydney, her primary teaching interests are object-oriented analysis and design. She is currently establishing a name for herself in IT education research, her research interests being information systems development and education, and improving the learning experience for all types of students. She is currently a $\mathrm{PhD}$ candidate. She is researching her topic, the dimensions of variation of understanding of business ISD, using a phenomenographic approach. 